\title{
ARTI KORBAN MENURUT KITAB IMAMAT
}

\author{
Ani Teguh Purwanto, M.Th. \\ Sekolah Tinggi Teologi Injili Indonesia Surabaya \\ E-mail:aniteguh@sttii-surabaya.ac.id
}

Abstract. Leviticus tells how sinful people can approach a holy God and how they live holy lives. To make atonement for their sins, God determines a series of sacrifices culminated in the sacrifices offered by the high priest. If you ignore the law and these statutes very severe punishment. Three core points: Yahweh dwells with the people of his choice, God is holy, so be holy Israel.

Keywords: Leviticus, approach, sacrifices, Yahweh

\section{PENDAHULUAN}

Kitab Imamat adalah kitab yang sukar untuk dipahami, sepintas kitab ini kurang menarik dan bahkan jarang dipelajari ataupun diajarkan. Kitab Imamat sering kali tidak mendapat banyak tanggapan, bahkan kitab Imamat dianggap tidak penting dan lebih lagi orang percaya terkesan mengabaikan kitab Imamat karena: Pertama, kitab ini sungguh-sungguh terasa asing bagi pembaca yang hidup pada masa kini. Persembahan-persembahan korban yang sangat ditekankan dalam kehidupan bangsa Israel terasa tidak penting bagi orang percaya saat ini sebab Tuhan Yesus sudah menggenapinya sebagai "kurban yang sempurna bagi Allah". Kedua, tampaknya kitab Imamat hanya mengatur persoalan ibadah dalam Perjanjian Lama dan sudah tidak relevan lagi bagi kebutuhan masyarakat modern saat ini. Walaupun tidak semua orang Kristen yang berpikir demikian.

Kitab Imamat di tulis oleh Musa, dan ada hubungannya langsung dengan kitab Keluaran. Dalam akhir kitab Keluaran, pembangunan Kemah Suci di ceritakan. "Kemah suci adalah pusat ibadah bangsa Israel, tempat dimana mereka menghadap TUHAN Allah."1 Kitab Imamat dimulai dengan "peraturan mengenai korban dan pelayanan kepada Tuhan yang harus dilaksanakan di Kemah Suci.”2

Dalam kitab Imamat, kita belajar bahwa dosa harus ditindak dan bahwa " Allah menuntut hidup kudus."3 Umat Allah harus berbeda dengan sesama manusia yang menyembah berhala, dan berbagai petunjuk khusus tentang kekudusan dan prilaku moral dapat diterapkan dalam banyak hal pada masa kini.

Kitab Imamat memberitahukan bagaimana umat yang berdosa dapat mendekati Allah yang kudus dan bagaimana mereka dapat hidup kudus. Untuk mengadakan pendamaian bagi dosa mereka, Tuhan menentukan serangkaian korban persembahan dan memuncak dalam korban yang dipersembahkan oleh imam besar. "Jika seseorang mengabaikan hukum dan ketetapan ini, hukumannya sangat berat."4 Inti dari teologi Kitab adalah : "Yahweh, yang berdiam bersama bangsa Israel, adalah Allah yang Kudus. Dan karena itu bangsa Israel harus Kudus."5

Meskipun kitab Imamat tidak menggelorakan semangat seperti halnya tulisan-tulisan Paulus tetapi kita akan mendapat banyak hal yang berarti jika membaca dan berusaha mengertinya. Karena jika kita perhatikan secara saksama, kitab Imamat adalah kitab yang paling banyak mengandung kata-kata Allah secara langsung dan juga kitab yang mengandung Injil. Misalnya Roy Gane dalam Commentarynya berkata:

\footnotetext{
${ }^{3}$ Herbert Wolf, Pengenalan Pentateukh. (Malang : Yayasan Penerbit Gandum Mas, 1998), p. 219

${ }^{4}$ Ibid., p. 220

${ }^{5}$ Carl A. Red, Teologi Of The Pentateuch.
}

${ }^{1}$ Carl. A Reed, Eksposisi Kitab Kejadian sampai dengan Ulangan. ( Yogyakarta : Sekolah Tinggi Teologi Injili Indonesia, 2000 ), p. 83

${ }^{2}$ Ibid. P. 83 
"True, this book of twenty-seven chapters contains more direct speech by God himself than any other book of the Bible and it is placed at the heart of the Torah or Pentateuch, which forms foundation for all of scripture. So even though Leviticus is the shortest book of the Pentateuch, we get the impression that it sould be important.

(Benar, kitab ini dua puluh tujuh pasal berisi suara langsung dari Allah sendiri dari kitab-kitab lain dari Alkitab dan ditempatkan di jantung Taurat atau Pentateukh, yang membentuk dasar bagi semua tulisan suci. Jadi meskipun Imamat adalah kitab terpendek Pentateukh, kita mendapatkan kesan bahwa kitab ini begitu penting). 6

Tafsiran Alkitab Masa Kini juga menyatakan, "Inilah Injil PB bagi pendosa yang dinyatakan dalam istilah PL dan diejawatahkan dalam upacara-upacara korban; dan diungkapkan secara sempurna dalam upacara Hari Pendamaian.7 Selain itu kitab Imamat mempunyai teologi yang masih sah dan relevan dengan kata lain betapa pentingnya kitab ini dalam kehidupan gereja masa kini. Ernst Aebi yang dikutip oleh Achim Teschner misalnya mengungkapkan; "Mungkin kitab Imamat adalah kitab yang paling sering disalahmengerti. Bagi kebanyakan pembaca kitab ini terkunci. Namun dengan keterangan PB, melalui kurban Yesus Kristus, kitab Imamat menjadi salah satu kitab PL yang paling penting dan menarik. 8

Pada penulisan paper ini, untuk mengerti kebenaran Alkitab penulis mencoba menjelaskan tentang arti korban, serta pentingnya korban bagi umat Israel pada jaman PL, serta penulis akan menguraikan hubungan antara korban dalam PL dengan Karya penebusan Kristus Tuhan kita. Harapan penulis ketika membaca paper ini, kecintaan kita akan Firman Allah akan bertambah dan biarlah paper pendek ini menolong untuk lebih lagi mendalami dan mengalami Firman Tuhan setiap waktu.

\section{LATAR BELAKANG KITAB IMAMAT}

${ }^{6}$ Roy Gane, The NIV Aplication Commentary, (Zondervan, Grand Rapids Michigan, 2004), p. 23.

7 Tafsiran Alkitab Masa Kini 1 Kejadian-Ester (Jakarta: YKBK, 2005), hal.188.

8 Achim Teschner, Diktat Pengantar Pentateukh, (STT IMAN, 1996), hal. 41.
Dalam beberapa bahasa di daratan Eropa, kitab ini disebut Leviticus, yang diambil dari bahasa Latin Liber Leviticus dari bahasa Yunani ( $\tau$ o) $\Lambda \varepsilon v ı \tau ı$ óv. "Imamat" berarti, "berhubungan dengan para imam atau orang Lewi."9 Dalam bahasa Ibrani, kitab ketiga dari Taurat ini disebut wayiqra yang artinya adalah "Maka dipanggil-Nya atau Ia memanggil" (Imamat 1:1). Kata wayiqra adalah awal kalimat pertama dalam kitab Imamat.

Secara umum Kitab Imamat ini menceritakan tentang bagaimana umat Allah yang sudah di tebus, hidup dihadapan Allah yang Mahakudus. Seperti halnya apa yang dikatakan Gowan yang dikutip oleh $\mathrm{R}$. Borrong, ia berkata "Penulis kitab Imamat menuntut agar umat Allah merefleksikan sifat Allah dalam kehidupan umat."10 Imamat, adalah nama kitab ketiga dari Pentateuch. Nama Imamat berasal dari Septuaginta melalui terjemahan Alkitab bahasa Latin, yang memberikan judul lengkap "kitab mengenai imam-imam".11 Kitab ini ditulis oleh Musa. Kitab ini terbagi atas 27 pasal dan merupakan kitab yang ketiga dari kitab-kitab Perjanjian Lama. Kitab Imamat pada dasarnya adalah kitab peraturan atau kitab hukum-hukum yang diberikan Allah kepada umat-Nya melalui Musa di Sinai. Sehingga jika kita perhatikan isi kitab yang mendominasi adalah peraturan. LaSor dkk misalnya menjelaskan bahwa Isi Kitab Imamat dapat dibagi menjadi 2 bagian besar yaitu: 1) Mengenai peraturan-peraturan tentang persembahan kepada Allah. Dan, 2) Peraturan di dalam kehidupan ibadah dalam persekutuan dengan-Nya.12 Dengan sepintas melihat pembagian Kitab imamat diatas bahwa Kitab Imamat terlihat suatu daftar peraturan.

\footnotetext{
${ }^{9}$ Herbert Wolf, Pengenalan Pentateukh. (Malang : Yayasan Penerbit Gandum Mas, 1998), p. 219

10 Robert P. Borrong, Berakar di dalam Dia dan dibangun di atas Dia (Jakarta: BPK Gunung Mulia, 2002), hal. 45. Tujuan Imamat ialah mengemukakan hukum-hukum dan asas-asas yang harus menjadi pedoman hidup Israel sebagai umat Allah. Tafsiran Alkitab Masa Kini 1 Kejadian-Ester (Jakarta: YKBK, 2005), hal.187.
}

${ }^{11}$ Jacob Milgrom, The Anchor Bible Leviticus 116 ( USA: Doubleday Published, 1991), hal. 134. Bnd. Lasor, W.S, Pengantar Perjanjian Lama 1, ( Jakarta: BPK.Gunung Mulia, 2001), hal.214.

$$
{ }^{12} \text { Lasor, W.S dkk, Pengantar Perjanjian Lama 1, ( }
$$

Jakarta: BPK.Gunung Mulia, 2001), p. 214 
Dari sini terlihat bahwa kitab Imamat adalah satu kitab yang berisikan peringatan dalam hal menjaga kekudusan sebagai umat Allah yang dinyatakan dengan berbagai peraturan salah satunya bagaimana mempersembahkan korban yang berkenan dihadapan Allah.

\section{ARTI KORBAN}

Tidak dapat disangkal setiap agama bahkan setiap orang yang dikatakan beragama mempunyai pemahaman tentang korban yang berbeda-beda. Maka tidak heran ada banyak variasi dalam menentukan makna korban. Perkataan korban berarti persembahan.

Korban dipahami sebagai persembahan kepada yang ilahi, sebagai pengganti manusia yang berdosa, atau santapan untuk dewa-dewa,dan sebagainya. Sistem korban ini secara tidak langsung mengungkapkan akan adanya sesuatu yang lebih besar dari manusia, karena korban itu dipersembahkan kepada sesuatu atau seseorang yang dianggap lebih besar dari manusia. Dan manusia yang menyadari akan kesalahan-kesalahannya, memberikan korban kepada sesuatu yang lebih besar ini, sehingga akibat dari kesalahan-kesalahan tidak lagi ditimpakan kepada manusia yang melakukan kesalahan. Perlu kita perhatikan konsep korban oleh orang kafir dengan konsep korban orang Israel pada hakekatnya sangat berbeda. G. E. Wright dan Kuiper dalam buku mereka menjelaskan bagaimana konsep orang kafir mengenai korban tidak lepas dari anggapan anthropomorf tentang dewa.

Dimana antara manusia dan dewa terdapat ikatan kekeluargaan dan persamaan, sehingga para dewa menyerupai manusia. Dewa bergantung pada manusia demikian sebaliknya manusia bergantung kepada dewa. Disini berlakulah dasar pokok do ut des (aku memberi agar engkau memberi).13 Namun lain halnya dengan korban dalam kitab Imamat sering dinyatakan untuk 'menebus'(Imamat 1:4, dst).14 Korban salah satu kelompok kata untuk 'persembahan' yang berasal dari kata kerja 'untuk

13 Dr. G.E. Wright \& Dr. A. De Kuiper, Perjanjian Lama Terhadap Sekitarnya (Bandung: Pinda Grafika, 1967), p. 122.

14 J.D Douglas, Esiklopedi Alkitab Masa Kini Jilid AL (Jakarta: YKBK 1992), hal. 579 membawa dekat."15 Korban adalah sarana umat untuk lebih mendekatkan diri kepada Allah bukan karena umat bermasud minta balasan berdasarkan korban yang sudah diberikan, melainkan korban itu adalah korban sukarela kepada Allah juga sebagai tebusan atas pelanggaran umat kepada Allah.

Membawa suatu persembahan / korban menunjukkan suatu korban atau pemberian dengan mana seseorang mendapat jalan masuk kepada Allah: dan ini mendapatkan terang dari kebiasaan universal yang berlaku di Timur, tak seorangpun diijinkan untuk mendekati seorang yang lebih tinggi tanpa suatu hadiah atau pemberian; dan persembahan yang dibawa itu disebut 'korban', yang secara benar berarti 'korban yang mempersiapkan jalan' atau 'korban jalan masuk'.

Namun penulis tidak sepenuhnya menerima ungkapan di atas karena menurut hemat penulis bahwa prinsip-prinsip di sini diberikan oleh Allah, bukan dari sistim agama lain, atau kebiasaan ibadat agama lain di sekitar Israel. Sekalipun kebiasaan universal yang dikatakan Clarke itu mungkin memang ada, itu tidak berarti bahwa peraturanperaturan di sini mendapatkan terang dari kebiasaan universal itu.

Menurut Imamat 7:37, ada lima korban yang termasuk dalam hukum dinyatakan Tuhan Allah kepada Musa di Gunung Sinai dan memerintahkan orang Israel mempersembahkan persembahan mereka di padang gurun Sinai. Kelima macam korban itu adalah korban bakaran, korban sajian, korban penghapus dosa, korban penebus salah dan korban keselamatan. Kelima macam korban tersebut mempunyai tujuan yang berbeda tetapi pada intinya sama yaitu sebagai pendamaian dan ucapan syukur. Dimana tindakan pendamaian di dalam kata ini berhubungan dengan sistim persembahan untuk menyelesaikan masalah dosa atau pelanggaran.

Selanjutnya untuk upacara korban Dyrness berpendapat bahwa:

"Upacara korban dalam Perjanjian Lama berpusat pada kata kerja bahasa Ibrani kipper yang biasanya diterjemahkan dengan "mendamaikan" atau "menutupi" (Imamat 1:4). Arti dasarnya barangkali

15 Merril C. Tenney, Pictorial Encyclopedia of the Bible Vol.4 Q-Z (Grand Rapids: The Zondervan Corporation, 1976), hal. 200. 
"menutupi" atau "menghapuskan". Atau kata kerja ini menunjuk kepada proses penebusan atau pendamaian dengan membayarkan sejumlah uang atau upeti, yang mencerminkan arti kata benda Ibrani koper ("harga tebusan"). Berdasarkan konteks alkitabiah (terutama Imamat 17:11), arti terakhir ini paling tepat mencerminkan konsep Ibrani."16

Jhon F. Walwoord dan Roy B. Zuck mengatakan :

Following the presentation of the victim was the laying on of hands, The worshiper was to lay (or "press" ) his hand on the head of the animal so that it would be accepted on his behalf to make atonement for him. The word translated " to lay his hand on " means "resting or supporting oneself " on the animal. Through this act the worshiper identified himself with the animal as his substitute.

Setelah presentasi dari korban penumpangan tangan, penyembah adalah untuk meletakkan (atau "tekan") tangannya di atas kepala binatang itu sehingga akan diterima atas namanya untuk membuat pendamaian bagi orang itu. Kata yang diterjemahkan "untuk meletakkan tangannya di" berarti "beristirahat atau mendukung diri" pada hewan. Melalui tindakan ini penyembah mengidentifikasi dirinya dengan binatang sebagai penggantinya. 17

Dari pengertian tersebut dapatlah dikatakan bahwa korban-korban yang dipersembahkan oleh Israel kepada Allah dalam Perjanjian Lama adalah merupakan pengganti (substitusi) nyawa mereka sendiri. Gagasan ini jelas terlihat dalam peristiwa korban-korban yang dicurahkan darahnya. Dalam hal ini, darah bukan unsur yang mengandung tenaga gaib, tetapi diterima Allah sebagai pengganti nyawa atau sebagai tebusan orang yang beribadah itu.

\section{PENTINGNYA KORBAN DALAM PL}

Melihat definisi korban itu sendiri sebenarnya sudah mengisyaratkan betapa pentingnya korban itu sendiri. Jika diperhatikan lebih jauh mengapa dalam kitab Imamat sangat ditekankan persembahan korban

${ }^{16}$ William Dyrness, Tema-Tema Dalam Teologi Perjanjian Lama, (Malang: Penerbit Gandum Mas, 1992), hlm. 133.

\footnotetext{
${ }^{17}$ Jhon F. Walvoord and Roy B. Zuck, The Bible Knowledge Commentary ( Old Testament), (Dallas : Dallas Seminary Faculty, 1985), p. 174
}

dimana pasal satu sampai pasal tujuh dengan detail membahas peraturan-peraturan persembahan korban yang harus dilakukan oleh umat Tuhan pada waktu itu, jelaslah betapa pentingnya korban itu di dalam Perjanjian Lama.

Jika kita perhatikan persembahan korban binatang merupakan tema penting dalam seluruh Kitab Suci. Ketika Adam dan Hawa berdosa, Allah mengorbankan binatang untuk menyediakan pakaian bagi mereka (Kejadian 3:21). Kain dan Habel membawa persembahan kepada Allah. Persembahan Kain tidak diterima karena dia mempersembahkan buah-buahan sedangkan persembahan Habel diterima karena dia mempersembahkan "anak sulung dari kambing dombanya" (Kejadian 4:4-5). Setelah banjir surut, Nuh mempersembahkan binatang kepada Allah. Persembahan Nuh ini merupakan persembahan yang berbau harum yang menyenangkan Tuhan (Kejadian 8:20-21). Allah memerintahkan Abraham untuk mempersembahkan Ishak anaknya. Abraham taat kepada Allah, namun ketika Abraham siap mempersembahkan Ishak, Allah campur tangan dan menyediakan seekor domba jantan untuk mati menggantikan Ishak (Kejadian 22:10-13). Korban adalah salah satu aspek yang sangat penting dalam ibadat orang Israel. Jhon F. Walvoord and Roy B. Zuck, The Bible Knowledge Commentary ( Old Testament) mengatakan :

This reveals the greatness of Abraham's faith ; he was willing to obey God by sacrificing his son. It also reveals the greatness of Isaac's faith in submission; he had everything in the world to live for but willingly followed his father's words, believing that God would provide a lamb. Ini menunjukkan kebesaran iman Abraham; ia bersedia untuk mematuhi Allah dengan mengorbankan anaknya. Ia juga mengungkapkan kebesaran iman Ishak dalam pengajuan; ia memiliki segala sesuatu di dunia untuk hidup tapi rela mengikuti kata-kata ayahnya, percaya bahwa Tuhan akan memberikan anak

domba.18

Sistem persembahan mencapai puncaknya pada zaman bangsa Israel. Allah memerintahkan bangsa ini untuk menjalankan berbagai persembahan. Seperti halnya yang diungkapkan Dr. G.E Wright; “ Ia telah memerintahkan agar kebaktian korban dilakukan sebagai cara untuk memuliakan nama-Nya, ini digunakan untuk

\footnotetext{
${ }^{18}$ Jhon F. Walvoord and Roy B. Zuck, The Bible Knowledge Commentary ( Old Testament), 1985. p., 65
} 
memelihara persekuatuan dengan Allah yaitu persekutuan yang terjadi oleh perjanjian.19 Menurut Imamat 1:1-4 ada prosedur tertentu yang harus diikuti dan tentunya ditaati. Pertama-tama, binatang tersebut harus tak bercacat. Kemudian orang yang mempersembahkan harus mengidentifikasikan atau menyamakan dirinya dengan binatang itu yang arti simbolisnya berarti kematian korban melambangkan kematian orang berdosa. Kemudian orang yang mempersembahkan harus membunuh binatang itu. Ketika dilakukan dengan iman, persembahan ini menyediakan pengampunan untuk dosa-dosa. Pulpit Commentary menjelaskan begini: "The offerer's faith is truly needful as the victim he brings. 'Without faith it is impossible to please God' (= Iman dari si pemberi korban sama perlunya seperti korban yang ia bawa. 'Tanpa iman tidak mungkin orang berkenan kepada Allah.') 20 Ibr 11:6 "Tetapi tanpa iman tidak mungkin orang berkenan kepada Allah". Dalam Imamat 4,5,6 dan 7 diuraikan kepada kita hukum-hukum korban penghapus dosa dan korban penebus salah. Korban penghapus dosa bermaksud memperbaiki hubungan dengan Allah kembali dan untuk menebus dosa. Korban penghapus dosa ini dipersembahkan pada hari Pendamaian Besar untuk menebus dosa pada imam dan segenap bangsa Israel. Sedangkan korban pengahapus salah adalah korban ganti rugi kepada orang yang dirugikan. Begitupun mengenai korban bakaran, korban sajian, dan korban keselamatan semuanya dijelaskan dengan detail dalam kitab Imamat. Lihat setiap korban memiliki rincian yang begitu rumit tetapi disitulah sebenarnya terdapat makna yang penting dan seorang imam serta si pemberi korban tidak boleh mengabaikannya. Tentunya bukan tidak ada alasan Alkitab mencatatnya ini menyatakan kepada kita bahwa konsep korban dalam PL sangat penting dan umat Tuhan tidak boleh melepaskannya dari kehidupan mereka.

Jadi dengan persembahan korban manusia diberi kesempatan untuk memuliakan dan menghormati Tuhan yang hidup, memelihara persekutuan dengan Dia dan melalui korban manusia diberi kesempatan menerima penebusan ketika manusia melakukan dosa tetapi itu adalah sementara. Namun korban khusunya dalam PL adalah sesuatu yang sangat penting dan begitu ditekankan.

\footnotetext{
${ }^{19}$ Wright \& Kuiper, Perjanjian Lama, hal. 122.

${ }^{20}$ http://www.golgothaministry.org/imamat/imamat-1_1-17.htm
}

\section{KORBAN DALAM PL MENGACU PADA PENGORBANAN KRISTUS}

Korban-korban dalam Perjanjian Lama hanya merupakan tebusan sementara untuk dosa dan takkan pernah dapat menjadikan umat yang mempersembahkan secara sempurna, seluruh umat para imam mereka juga harus mempersembahkan korban dari tahun ke tahun. Karena inilah kehendak Allah kepada umat-Nya. Namun usaha manusia yang bersifat agamawi tidak dapat membuat mereka masuk ke dalam keadaan yang layak di hadapan Allah yang maha kudus.

Kelayakan tersebut sepenuhnya datang dari Allah.Dosa memang merusak hubungan manusia dengan Allah dan menjadikan rintangan bagi manusia untuk datang kepada Allah. Kitab Imamat memberikan gambaran bahwa untuk mengatasi rintangan yakni dengan ibadat korban. Hal ini merupakan sifat yang asasi dari Allah dalam Perjanjian Lama maupun Perjanjian Baru. Korban dalam Kitab Imamat mempunyai pembatasan sebab hanya bisa menghapus dosa yang tidak disengaja atau bahkan ini hanya bersifat ritual. Berbeda dengan konsep korban dalam perjanjian Baru.

Paulus menekankan bahwa Kematian Yesus di kayu salib menyatakan kebenaran dan keadilan Allah.21 Penulis surat Ibrani menyatakan dengan sangat jelas adalah korban yang satu-satunya yang perlu membebaskan kita dari dosa, dan korban Tuhan Yesus bersifat kekal atau selamanya. Hal ini membuktikan bahwa Allah tidak mau manusia binasa. Oleh karena itu Kristus telah mati sebagai korban yang dipersembahkan oleh Allah untuk memenuhi tuntutan keadilan Allah yang dinyatakan untuk penyelesaian dosa manusia. Dengan demikian keberadaan manusia diperdamaikan kembali dengan Allah dan manusia melalui pengorbanan Tuhan Yesus kembali memperoleh keberadaan manusia sebelum manusia berdosa. Korban identik dengan persembahan yang dimana ada tujuan yang hendak dicapai. Korban dalam kitab Imamat membawa kita pada pengertian tentang penebusan Kristus bagi dosa

manusia.

Pendamaian darah dan kekudusan hidup yang begitu ditekankan dalam kitab Imamat sangat erat

\footnotetext{
${ }^{21}$ Robert Peterson, Tafsiran Kitab Imamat (Jakarta: BPK Gunung Mulia, 1994), hal. 79.
} 
kaitannya dengan karya pendamaian Kristus dan kekudusan hidup orang percaya dalam perjanjian baru. Perjanjian Baru mengajarkan bahwa darah pendamaian dari binatang yang dikorbankan, hal yang menonjol dalam kitab Imamat, hanyalah "bayangan saja dari keselamatan yang akan datang" (Ibr 10:1) dan menunjuk kepada Kristus sebagai korban penghapus dosa yang dipersembahkan satu kali untuk selama-lamanya (Ibr 9:12). Perintah untuk hidup kudus dapat dicapai sepenuhnya oleh orang percaya melalui darah Kristus yang mahal (1 Ptr $1: 15)$.

Coba perhatikan ruang yang Allah berikan untuk Kitab Imamat. Hanya 27 ayat dalam Kejadian yang digunakan untuk menjelaskan seluruh Penciptaan, tetapi ada 27 fasal yang dibutuhkan untuk menjelaskan bagaimana kita menjalani kehidupan yang berkenan kepada Tuhan. Selain itu, kitab ini dikutip lebih dari 80 kali dalam Perjanjian Baru. Korban-korban dalam Kitab Imamat merupakan penjelasan yang paling lengkap dalam seluruh Alkitab mengenai karya penebusan Juruselamat bagi dosa manusia.

Pada akhirnya terlihat bahwa semua ketentuan peribadatan Perjanjian Lama bersifat sementara. Ia harus selalu diulang-ulang. Penulis kitab Ibrani selanjutnya menyebutkan bahwa tindakan peribadatan ataupun korban-korban yang dipersembahkan secara berulang-ulang di dalam Perjanjian Lama justru menunjukkan bahwa korban tersebut sama sekali tidak dapat menghapuskan dosa. Itu sebabnya, diperlukan suatu pengorbanan yang sempurna yang hanya satu kali dilakukan dan hal itu menunjuk kepada Kristus sendiri (Ibrani 10:11-12). Seperti halnya yang di ungkapkan LaSor dkk : "Dalam Perjanjian Baru kurban berupa kambing dan domba dianggap lambang saja, "sebab tidak mungkin darah lembu jantan atau darah domba jantan menghapuskan dosa (Ibr. 10:4). Sedangkan, darah Kristus yang

dipersembahkan sekali untuk selama-lamanya merupakan kurban yang sempurna."22 Selanjutnya hari raya-hari raya Israel melukiskan tentang tindakan penyelamatan Allah di dalam waktu yang pernah mereka lalui. Paskah misalnya merupakan hari raya yang dilakukan sebagai peringatan terhadap tindakan penyelamatan yang dilakukan Allah terhadap Israel dari perbudakan Mesir. Dengan hari raya-hari raya tersebut, Israel memperingati bahwa Tuhan yang telah melepaskan mereka di masa

\footnotetext{
${ }^{22}$ W.S Lasor ,dkk, Pengantar Perjanjian Lama 1, ( Jakarta: BPK.Gunung Mulia, 2001), p. 220
}

lampau.23 Uniknya, 1 Korintus 5:7 menyebutkan secara jelas bahwa domba Paskah itu menunjuk kepada diri Kristus sendiri. Jadi di sini pun jelas terlihat bahwa baik upacara keagamaan maupun hari raya-hari raya yang diwajibkan kepada Israel pada masa Musa (diturunkannya Taurat) merujuk kepada keselamatan yang akan datang atau diwujudkan kelak di dalam Tuhan Yesus Kristus. R. Laird Harris berkata: " The need for for various sacrifices arises from the varied needs of a people's worship. The New Testament makes clear that all the sacrifices of Israel were symbolic and typical of Christ's sacrifice." (Kebutuhan untuk berbagai pengorbanan timbul dari beragam kebutuhan ibadah rakyat. Perjanjian Baru membuat penjelasan bahwa semua pengorbanan Israel ini adalah simbolis dan khas/tipikal dari pengorbanan Kristus.)15 Jelaslah kepada kita bahwa konsep korban dalam PL sebenarnya adalah gambaran dari korban yang di berikan Kristus yang menebus dosa. Yesus Kristuslah yang mendamaikan kita dengan Allah. Dia menderita dan mati sebagai korban yang tak bercacat bagi manusia yang berdosa

\section{KESIMPULAN}

Kitab Imamat dalam beberapa bahasa di daratan Eropa, kitab ini disebut Leviticus, yang diambil dari bahasa Latin Liber Leviticus dari

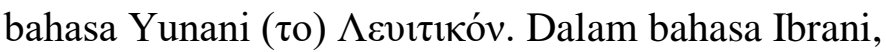
kitab ketiga dari Taurat ini disebut wayiqra yang artinya adalah "Maka dipanggil-Nya atau Ia memanggil" (Imamat 1:1). Kata wayiqra adalah awal kalimat pertama dalam kitab Imamat. ${ }^{[1][2]}$ Kitab ini berisi peraturan-peraturan untuk ibadat dan upacara-upacara agama bangsa Israel pada zaman dahulu. Juga untuk para imam (kaum Lewi) yang bertanggung jawab atas pelaksanaannya. Dicatat di dalamnya bahwa Kitab ini secara khusus memuat "perintah-perintah yang diperintahkan TUHAN kepada Musa di gunung Sinai untuk disampaikan kepada orang Israel". Yang menjadi pokok dalam buku ini ialah kesucian Tuhan, dan bagaimana manusia harus hidup dan beribadat supaya tetap mempunyai hubungan baik dengan Yahweh, Tuhan Israel. Seluruh korban dalam PL menunjuk kepada satu korban, yaitu Kristus, yang selama-lamanya menghapus dosa seluruh dunia. Korban-korban itu menjadikan kematian Kristus penting dalam rencana

\footnotetext{
${ }^{23}$ William Dyrness, Tema-Tema DalamTeologi Perjanjian Lama, (Malang : Gandum Mas, 2013), p. 131
} 
keselamatan dari Allah. Jadi makna sistem korban itu intinya sebenarnya mengacu pada pengorbanan Yesus di kayu salib sebagai tebusan bagi dosa umat manusia. Korban dalam kitab Imamat ini penting karena memberikan kepada kita latar belakang untuk memahami kebenaran sentral iman Kristen mengenai pengorbanan Kristus yang menebus kita dari dosa.

\section{KEPUSTAKAAN}

Borrong, Robert P., Berakar di dalam Dia dan dibangun di atas Dia (Jakarta: BPK Gunung Mulia, 2002).

Douglas, J.D., Esiklopedi Alkitab Masa Kini Jilid AL (Jakarta: YKBK 1992).

Dyrness, William. Tema-Tema Dalam Teologi Perjanjian Lama, (Malang: Penerbit Gandum Mas, 1992).

Gane, Roy. The NIV Aplication Commentary, (Zondervan, Grand Rapids Michigan, 2004).

http://www.golgothaministry.org/imamat/imamat$1 \_1-17 . h t m$

Lasor, W.S dkk, Pengantar Perjanjian Lama 1, ( Jakarta: BPK.Gunung Mulia, 2001).

Reed, Carl A., Eksposisi Kitab Kejadian sampai dengan Ulangan. ( Yogyakarta : Sekolah Tinggi Teologi Injili Indonesia, 2000 ).

Red, Carl A., Teologi Of The Pentateuch. (Yogyakarta : Sekolah Tinggi Teologi Injili Indonesia, 2014).

Teschner, Achim, Diktat Pengantar Pentateukh, (STT IMAN, 1996).

Tenney, Merril C., Pictorial Encyclopedia of the Bible Vol.4 Q-Z (Grand Rapids: The Zondervan Corporation, 1976).

Tafsiran Alkitab Masa Kini 1 Kejadian-Ester (Jakarta: YKBK, 2005).

Peterson, Robert. Tafsiran Kitab Imamat (Jakarta: BPK Gunung Mulia, 1994).
.Tafsiran Alkitab Masa Kini 1 Kejadian-Ester (Jakarta: YKBK, 2005).

Wolf, Herbert. Pengenalan Pentateukh. (Malang : Yayasan Penerbit Gandum Mas, 1998).

Wright G.E., \& De Kuiper, Perjanjian Lama Terhadap Sekitarnya (Bandung: Pinda Grafika, 1967).

Walvoord Jhon F., and Roy B. Zuck, The Bible Knowledge Commentary ( Old Testament), (Dallas : Dallas Seminary Faculty, 1985). 